\title{
Killed Bifidobacterium longum enhanced stress tolerance and prolonged life span of Caenorhabditis elegans via DAF-16
}

\author{
Takaya Sugawara and Kazuichi Sakamoto* \\ Graduate School of Life and Environmental Sciences, University of Tsukuba, 1-1-1 Tennoudai, Tsukuba, Ibaraki \\ 305-8572, Japan \\ (Submitted 13 February 2018 - Final revision received 7 May 2018 - Accepted 8 May 2018 - First published online 4 September 2018)
}

\begin{abstract}
Probiotics are bacteria among the intestinal flora that are beneficial for human health. Bifidobacterium longum (BL) is a prototypical probiotic that is widely used in yogurt making, supplements and others. Although various physiological effects of BL have been reported, those associated with longevity and anti-ageing still remain elusive. Here we aimed to elucidate the physiological effects of killed BL (BR-108) on stress tolerance and longevity of Caenorhabditis elegans and their mechanisms. Worms fed killed BL in addition to Escherichia coli (OP50) displayed reduced body length in a BL dose-dependent manner. When compared with those fed $E$. coli alone, these worms had a higher survival rate following heat stress at $35^{\circ} \mathrm{C}$ and hydrogen peroxide-induced oxidative stress. A general decrease in motility was observed over time in all worms; however, killed BL-fed ageing worms displayed increased movement and longer life span than those fed $E$. coli alone. However, the longevity effect was suppressed in sir-2.1, daf-16 and skn-1-deficient worms. Killed BL induced DAF-16 nuclear localisation and increased the expression of the DAF-16 target gene hsp-12.6. These results revealed that the physiological effects of killed BL in C. elegans were mediated by DAF-16 activation. These findings contradict previous observations with different Bifidobacterium and Lactobacillus strains, which showed the role for SKN-1 independently of DAF-16.
\end{abstract}

Key words: Bifidobacterium longum: Killed bacteria: BR-108: Longevity: Stress tolerance: daf-16

Caenorhabditis elegans feeds on Escherichia coli as food and lives for approximately 1 month on a nematode growth medium (NGM) plate. C. elegans is a commonly used model organism owing to its transparent body and ease of culture ${ }^{(1)}$. In addition, its short life span and genetic similarity with higher animals renders it suitable for studying longevity and as a model organism for various biological assays. Furthermore, its genome and cell lineages are well described. Lately, it has been used to evaluate the effect of certain food and their related functional components, including the anti-ageing effect of nucleoprotein extracted from salmon milt ${ }^{(2)}$, longevity and stress tolerance effects of catalpol extracted from rehmannia roots ${ }^{(3)}$, longevity effect of oreanolic acid ${ }^{(4)}$ and others by feeding them along with $E$. coli to $C$. elegans.

The first longevity genes described in budding yeast, C. elegans and Drosophila were the sirtuin genes. Longevity genes such as SIR2 and TOR1 of budding yeast ${ }^{(5,6)}$; sir-2.1, daf-16 and age-1 of C. elegans ${ }^{(7,8)}$; and Sir2 and $d F O X O$ of Drosophila ${ }^{(9)}$ are well described. These genes mediate longevity ${ }^{(10-12)}$, lower the reactive oxygen species (ROS) level ${ }^{(3,13)}$, suppress ageing ${ }^{(2)}$ and increase stress tolerance ${ }^{(3,4)}$. For example, activated DAF-16 translocates into the nucleus and acts as a transcription factor ${ }^{(14)}$ for genes related to stress tolerance, such as $\operatorname{sod}-3^{(15,16)}$ and $h s p-12.6^{(17)}$. Up-regulation of these genes prolongs the life span of the nematode and increases stress tolerance ${ }^{(11,18)}$. Conversely, deficiency of these genes shortens the life span and decreases stress tolerance ${ }^{(19,20)}$. Longevity genes are also found in higher animals. For example, humans possess approximately fifty members of the FOX transcription factors ${ }^{(21,22)}$. FOxO, a member of the FOX transcription factor family, is the homologue of the C. elegans daf-16 ${ }^{(23)}$ and Drosophila $d F O X O^{(24)}$.

In 1908, Metchnikoff first described that Bulgarians ingesting Lactobacillus regularly by consuming yogurt showed longevity ${ }^{(25,26)}$. This is the first description of the association between longevity and probiotics. Bifidobacterium is a wellknown probiotic and constitutes the majority of the intestinal flora in infants ${ }^{(27)}$. Although the proportion is reduced after infancy, the number of Bifidobacterium longum (BL) in the intestine is 100-1000 times higher than that of Lactobacillus ${ }^{(27)}$, and $\mathrm{BL}$ is known to promote the health of the host. Recent studies have described several physiological effects of BL, such as to regulate intestinal function and its beneficial effects in immunity and allergy reduction ${ }^{(28,29)}$. Furthermore, the role of Bifidobacterium in suppression of cancer has been reported ${ }^{(30)}$.

\footnotetext{
Abbreviations: BL, Bifidobacterium longum; ROS, reactive oxygen species.
} 
Despite the potential benefits of Bifidobacterium mentioned above, its physiological effects on longevity and anti-ageing and their mechanisms are not well described. Here, we evaluated the effects of heat-killed BL (BR-108). Killed bacteria were used in this study, considering bacteria ingested by humans are likely to be killed by digestive juices. We aimed to analyse the physiological effects of $\mathrm{BL}$ on stress tolerance, anti-ageing and longevity in C. elegans and their mechanisms.

\section{Methods}

\section{Nematode and Bifidobacterium}

C. elegans strains used in this study were as follows: N2 Bristol (wild type), daf-16 (mgDf50), sir-2.1 (ok434), skn-1 (tm4241), col-19::GFP (TP12), daf-16::GFP (TJ356) (obtained from the Caenorhabditis Genetics Center, University of Minnesota) and skn-1 (tm 4241) (obtained from the National BioResource Project, Tokyo Women's Medical University). The nematodes were cultured at $20^{\circ} \mathrm{C}$ on NGM plates spread with E. coli $(\mathrm{OP} 50)^{(1)}$. $\mathrm{BL}$ (BR-108) sterilised at $105^{\circ} \mathrm{C}$ for 20 min was obtained from the Combi Corporation.

\section{Nematode synchronisation}

To collect eggs, adult nematodes were crushed in $\mathrm{NaClO}$ solution (1:10 of $10 \mathrm{~m} \mathrm{NaOH}$ (Wako Pure Chemical Industries, Ltd) and $\mathrm{NaClO}$ (Haiter; KAO)). This method was used to synchronise the nematode growth level.

\section{Body length measurement}

Synchronised worms were placed on NGM plates spread with OP50 only (OP plates) or along with $\mathrm{BL}$ at various concentrations (BL plates; $1 \cdot 0,2 \cdot 0,3 \cdot 0$ or $5 \cdot 0 \mathrm{mg} / \mathrm{ml}$ ) and cultured at $20^{\circ} \mathrm{C}$ for $96 \mathrm{~h}$. Thereafter, the worms were fixed with $10 \%$ ethanol (Kanto Chemical Co., Inc.) and observed under a BZ8000 microscope (Keyence Corporation). Body length was determined using the Image software (NIH). The body length of the control worms was set as $100 \%$ and > 30 worms were evaluated per group.

\section{Measurement of COL-19 expression}

COL-19 expression was used as the indicator for ageing, and adult col-19:: GFP (TP12) worms expressing fluorescent COL-19 protein were used in the experiment. Synchronised TP12 worms were cultured on $\mathrm{OP}$ or BL plates $(0.5$ or $5.0 \mathrm{mg} / \mathrm{ml})$ at $20^{\circ}$ $\mathrm{C}$ for $52 \mathrm{~h}$. Thereafter, the worms were fixed with $10 \%$ ethanol and observed under a BZ8000 microscope. The fluorescence was analysed using the Image software. The fluorescence of control worms was set as $100 \%$ and $>25$ worms were evaluated per group.

\section{Evaluation of nematode motility}

The movement of wild-type, $M g D f 50$ and $t m 4241$ worms was evaluated. Synchronised worms were cultured on OP plates for $96 \mathrm{~h}$ and then transferred to OP or BL plates $(0.5$ or $5.0 \mathrm{mg} / \mathrm{ml})$. The day of the initial transfer to OP or BL plates was designated as day 0 . The worms were then transferred to new plates every $3 \mathrm{~d}$ and thrashing movement of the worms was counted on each transfer day. To prevent offspring generation, $0.5 \mathrm{mg} / \mathrm{ml} \mathrm{FUdR}$ (2'-deoxy-5-fluorouridine; Wako Pure Chemical Industries, Ltd) was added into the plates at days $-1,0$ and 3 . The movement at day 0 was set as $100 \%$ and 10 worms were evaluated per group.

\section{Assessment of heat stress tolerance}

Synchronised worms were cultured on OP or BL plates $(0.5$ or $5.0 \mathrm{mg} / \mathrm{ml}$ ) at $20^{\circ} \mathrm{C}$ for $96 \mathrm{~h}$ and then incubated at $37^{\circ} \mathrm{C}$ for $3.5 \mathrm{~h}$. The day of heat application was designated as day 0 . As described above, $0.5 \mathrm{mg} / \mathrm{ml} \mathrm{FUdR}$ was applied to the plates at days -1 and 0 . The survival rate of thirty worms/group was evaluated every $2 \mathrm{~d}$.

Generally, heat stress decreased the worm movement. To measure the recovery rate from heat stress, synchronised worms were cultured on OP or BL plates $(0.5$ or $5.0 \mathrm{mg} / \mathrm{ml})$ for $96 \mathrm{~h}$ and then transferred to $\mathrm{OP}$ plates and incubated at $35^{\circ} \mathrm{C}$ for $4 \mathrm{~h}$. The time of heat application was designated as the $0 \mathrm{~h}$, and thrashing movement was counted every $12 \mathrm{~h}$. In parallel, the movement of worms kept at $20^{\circ} \mathrm{C}$ instead of $35^{\circ} \mathrm{C}$ was counted. The ratio of movement count of worms cultured at $35^{\circ} \mathrm{C}$ and $20^{\circ} \mathrm{C}$ was calculated and the results are presented. The movement of ten worms/group was counted.

Table 1. Sequences of primers used in the gene expression analysis

\begin{tabular}{lll}
\hline Genes & 5'-3' Sense & 5'-3' Anti-sense \\
\hline Actin & TCGGTATGGGACAGAAGGAC & CATCCCAGTTGGTGACGATA \\
saf-16 & ATCATCTTTCCGTCCCCG & TTGGAATTGCTGGAACCG \\
$h s p-12.6$ & GCTGCAATCTACTGCTCGCACTG & GGCTGATTACAGGTTCCAAATCTGC \\
$h s p-16.2$ & TGGAGTTGTCAATGTCCTCG & GACTTCAATCTCTTTTGGAGG \\
$h s p-70$ & TGTTGGTGCAGTTGCTTCGAATC & TTCTCTTCGACGATTGCCTGTTG \\
$r a b-10$ & ACCCTTCGTTGGATGGAACG & GCATCCGGAACCTGATTGGGC \\
$s k n-1$ & TATTACCGCGGAGCAATGGG & TCTTCCGATGCATGTTCGTCA \\
$i n s-39$ & TTCAAACTCCCACCCGAATGT & TGGTGTTGGTGGTGGAGAG \\
sod-1 & CGTCCGACTTCATCCCTCAC & GCTGAGCAGAAGACCAGGAG \\
$p h a-4$ & TGGTGGACCAAAATCCGAGA & CCATAGATCGGCCAACGACA \\
$m y o-2$ & CTCGGCCGCCAACCTATAAA & CGGTTGAAACCAATGGCAGG \\
$c t l-1$ & CCCTCGATCGTCAGACACAG & GGAGTCATATGCGCGGGATT \\
$c t-2$ & GTCGTTCATGCCAAGGGAG & ACGAACGAGAAGTGGTCT \\
\hline
\end{tabular}


(a)

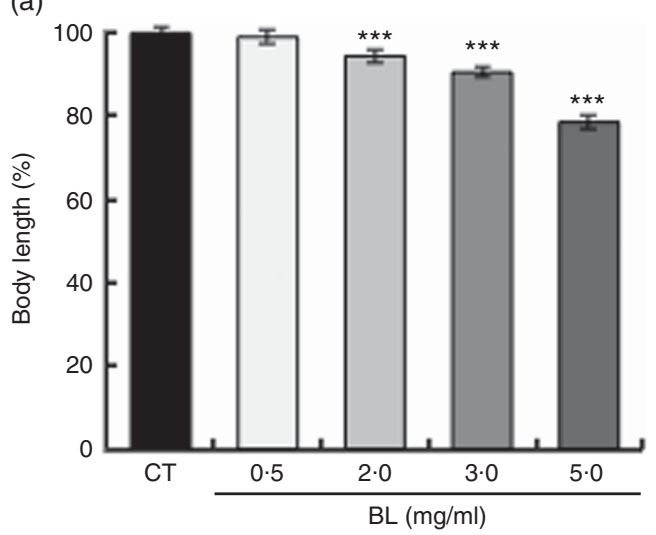

(b)

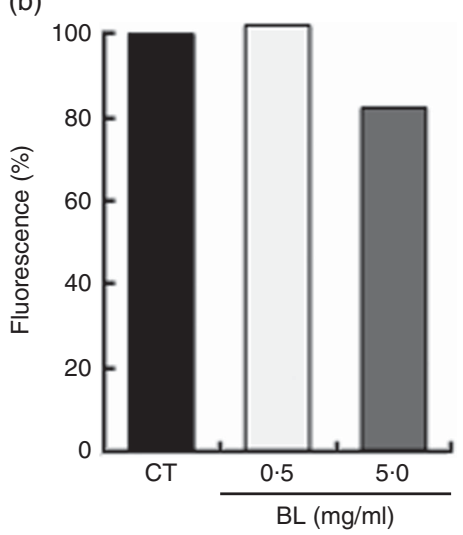

Fig. 1. Effects of Bifidobacterium longum (BL) on worm growth and development. (a) Synchronised worms were placed on plates containing Escherichia coli (OP50) alone (OP plates; CT) or with different concentrations of killed BL (1.0, 2.0, 3.0 or $5.0 \mathrm{mg} / \mathrm{ml}$ ). Worms were cultured on these plates for $96 \mathrm{~h}$. (b) Synchronised TP12 worms were cultured on OP (CT) or BL plates $(0.5$ or $5.0 \mathrm{mg} / \mathrm{ml})$ for $52 \mathrm{~h}$. In both assays, the worms were fixed in $10 \%$ ethanol and observed under a microscope to assess body length and fluorescence. The body length and fluorescence of control worms were set as $100 \%$. Values are means $(n>30$ and $n>25$ for the two assays, respectively), with their standard errors represented by vertical bars. ${ }^{* \star *} P<0.005$ by Tukey's $t$ test.

In addition to that in wild-type worms, the recovery from heat stress in $m g D f 50$ and tm 4211 mutant worms was also evaluated using the method described above. The worms were cultured on $\mathrm{OP}$ or BL plates $(5.0 \mathrm{mg} / \mathrm{ml})$, and thrashing movement of $m g D f 50$ and tm4211 worms was counted every 12 and $6 \mathrm{~h}$, respectively. The movement of 10 worms/group was counted.

\section{Evaluation of oxidative stress tolerance}

Synchronised worms were cultured on OP or BL plates $(0.5$ or $5.0 \mathrm{mg} / \mathrm{ml}$ ) for $96 \mathrm{~h}$ and then transferred to $500 \mu \mathrm{l}$ of $0.3 \% \mathrm{H}_{2} \mathrm{O}_{2}$ (Sigma-Aldrich Japan) in a 24-well plate (Techno Plastic Products AG). The time of transfer was designated as the $0 \mathrm{~h}$. The worm survival rate was determined every hour starting from $2 \mathrm{~h}$ after the transfer. The survival rate at $0 \mathrm{~h}$ was set as $100 \%$, and 24 worms were assessed per group.

Tolerance to oxidative stress in $m g D f 50$ and $t m 4211$ worms was also evaluated using the method described above. The worms were cultured on OP or BL plates $(5.0 \mathrm{mg} / \mathrm{ml})$ and 24 worms were assessed per group.

\section{Evaluation of life span}

Synchronised worms were cultured on OP plates for $96 \mathrm{~h}$ and then transferred to $\mathrm{OP}$ or BL plates $(5.0 \mathrm{mg} / \mathrm{ml})$. The day of the initial transfer to $\mathrm{OP}$ or BL plates was designated as day 0. The worms were then transferred to new plates every $2 \mathrm{~d}$. Alive and dead worms were counted on each transfer day. Worms that displayed no movement upon gentle probing with a platinum picker were judged as dead. As described above, $0.5 \mathrm{mg} / \mathrm{ml} \mathrm{FUdR} \mathrm{was} \mathrm{added} \mathrm{into} \mathrm{the}$ plates at days $-1,0,2$ and 4 . In addition to that of wild-type worms, the life span of $M g D f 50$, ok434 and tm4241 worms was also assessed. The survival rate of sixty worms/group was determined.

\section{Evaluation of fat accumulation}

Synchronised worms were cultured on OP or BL plates $(0.5$ or $5.0 \mathrm{mg} / \mathrm{ml}$ ) for $96 \mathrm{~h}$ and then fixed with $4 \%$ PFA (Wako Pure Chemical Industries, Ltd) at $4^{\circ} \mathrm{C}$. Fixed worms were washed and
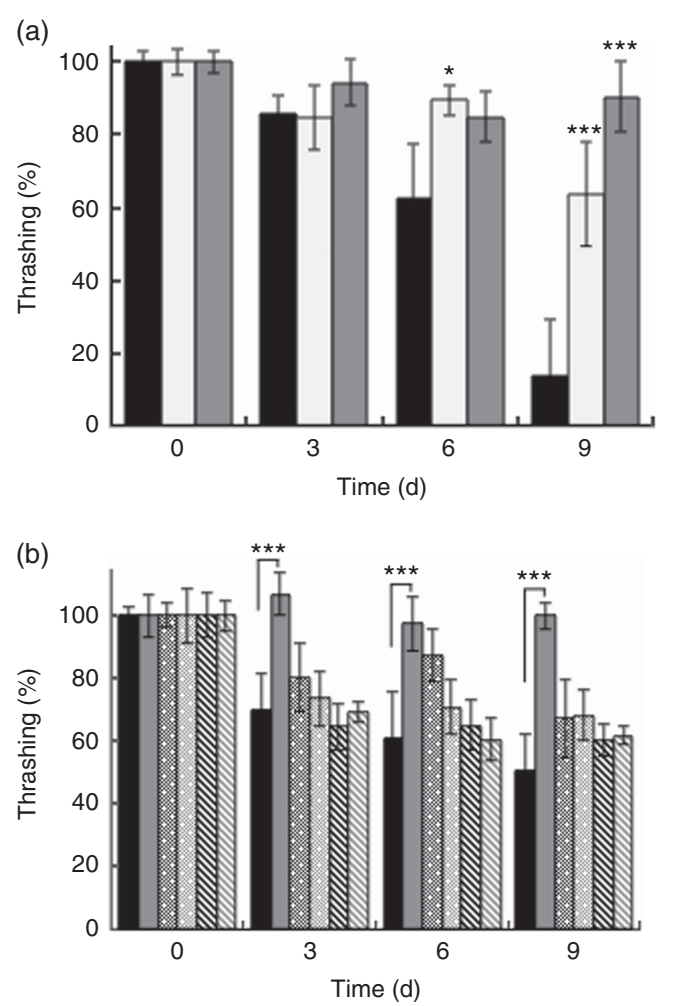

Fig. 2. Effects of Bifidobacterium longum (BL) on worm movement. Synchronised (a) N2 worms or (b) N2, MgDf50 and tm4241 worms were cultured on plates with Escherichia coli (OP50) (OP plates) for $96 \mathrm{~h}$ and then transferred to OP plates (CT) or plates with killed BL (a: 0.5 or $5.0 \mathrm{mg} / \mathrm{ml}$; b: $5.0 \mathrm{mg} / \mathrm{ml}$ ), which was designated as day 0 . The worms were then transferred to new plates every $3 \mathrm{~d}$ and thrashing movement of the worms was counted on each transfer day. To prevent offspring generation, $0.5 \mathrm{mg} / \mathrm{ml} \mathrm{FUdR} \mathrm{was} \mathrm{added} \mathrm{to} \mathrm{the}$ plates at days $-1,0$ and 3 . The movement count at day 0 was set as $100 \%$. Values are means ( $n 10$ per group), with their standard errors represented by vertical bars. a: $\square$, CT; $\square$, BL 0.5; $\square$, BL 5.0 (mg/ml); b: $\square$, CT (N2); $\square$, BL 5.0 (N2); \$, CT (mgDf50); 图, BL 5.0 (mgDf50); \$, CT (tm4241); 图, BL 5.0 (tm4241) (mg/ml). ${ }^{*} P<0.05$, ${ }^{* \star *} P<0.005$ by Tukey's $t$ test.

then placed in plates containing $500 \mu \mathrm{l}$ of $5 \mu \mathrm{g} / \mathrm{ml} \mathrm{Nile} \mathrm{red} \mathrm{(Wako}$ Pure Chemical Industries, Ltd) for $10 \mathrm{~min}$ at $4^{\circ} \mathrm{C}$. Subsequently, the worms were washed again twice and fluorescence was 
(a)

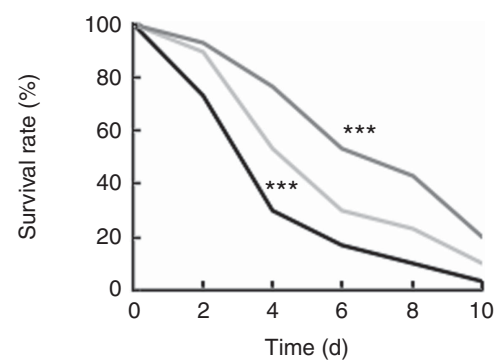

(c)

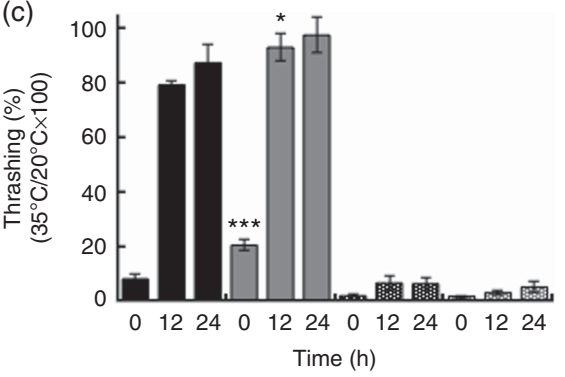

(b)

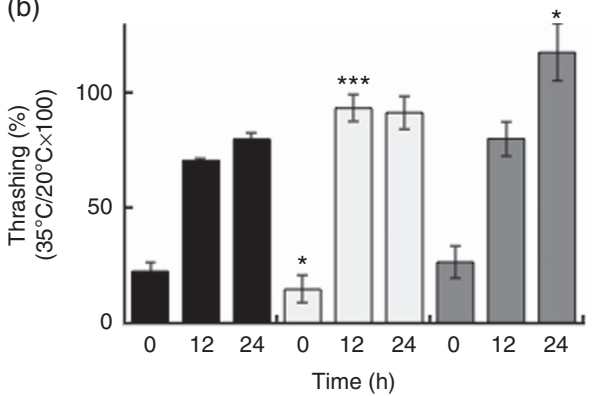

(d)

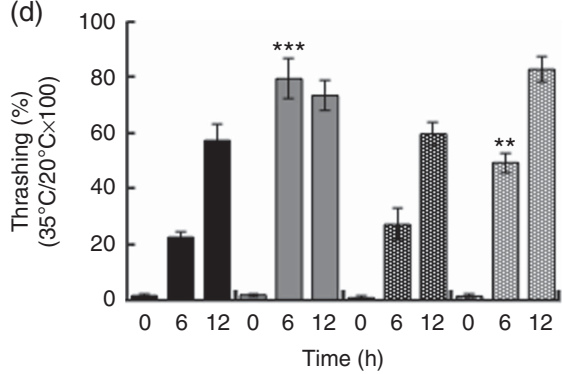

Fig. 3. Heat stress tolerance of worms fed Bifidobacterium longum (BL). (a) Synchronised wild-type N2 worms were cultured on plates with Escherichia coli (OP50) alone (OP plates; CT) or with killed BL (BL plates; 0.5 or $5.0 \mathrm{mg} / \mathrm{ml}$ ) for $96 \mathrm{~h}$ and then heated at $37^{\circ} \mathrm{C}$ for $3.5 \mathrm{~h}$, which was designated as day 0 . To prevent offspring generation, $0.5 \mathrm{mg} / \mathrm{ml} \mathrm{FUdR}$ was added into the plates at days -1 and 0 . The worm survival was recorded every $2 \mathrm{~d}, n 30 /$ group. ${ }^{\star \star \star} P<0.005$ by log-rank test. (b-d) Synchronised wild-type N2 worms, as well as $m g D f 50$ (c) and tm 4211 worms (d), were cultured on OP (CT) or BL plates (b, 0.5 or $5.0 \mathrm{mg} / \mathrm{ml} ; \mathrm{c}-\mathrm{d}, 5.0 \mathrm{mg} / \mathrm{ml}$ ) for $96 \mathrm{~h}$ and then transferred to OP plates and either left at $20^{\circ} \mathrm{C}$ or heated at $35^{\circ} \mathrm{C}$ for $4 \mathrm{~h}$ (the time of heat application was designated as $0 \mathrm{~h}$ ). Thrashing movement was counted every 12 or $6 \mathrm{~h}$. The ratio of movement count of worms cultured at $35^{\circ} \mathrm{C}$ and $20^{\circ} \mathrm{C}$ was calculated. Values are means ( $n 10$ per group), with their standard errors represented

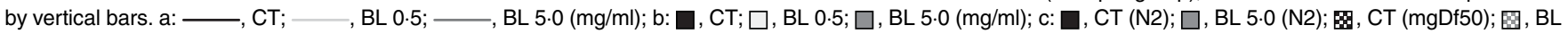
5.0 (mgDf50) (mg/ml); d: $\square$, CT (N2); $\square$, BL 5.0 (N2); 7 , CT (tm4241); 图, BL 5.0 (tm4241) (mg/ml). ${ }^{*} P<0.05,{ }^{* *} P<0.01,{ }^{* * *} P<0.005$ by Tukey's $t$ test.
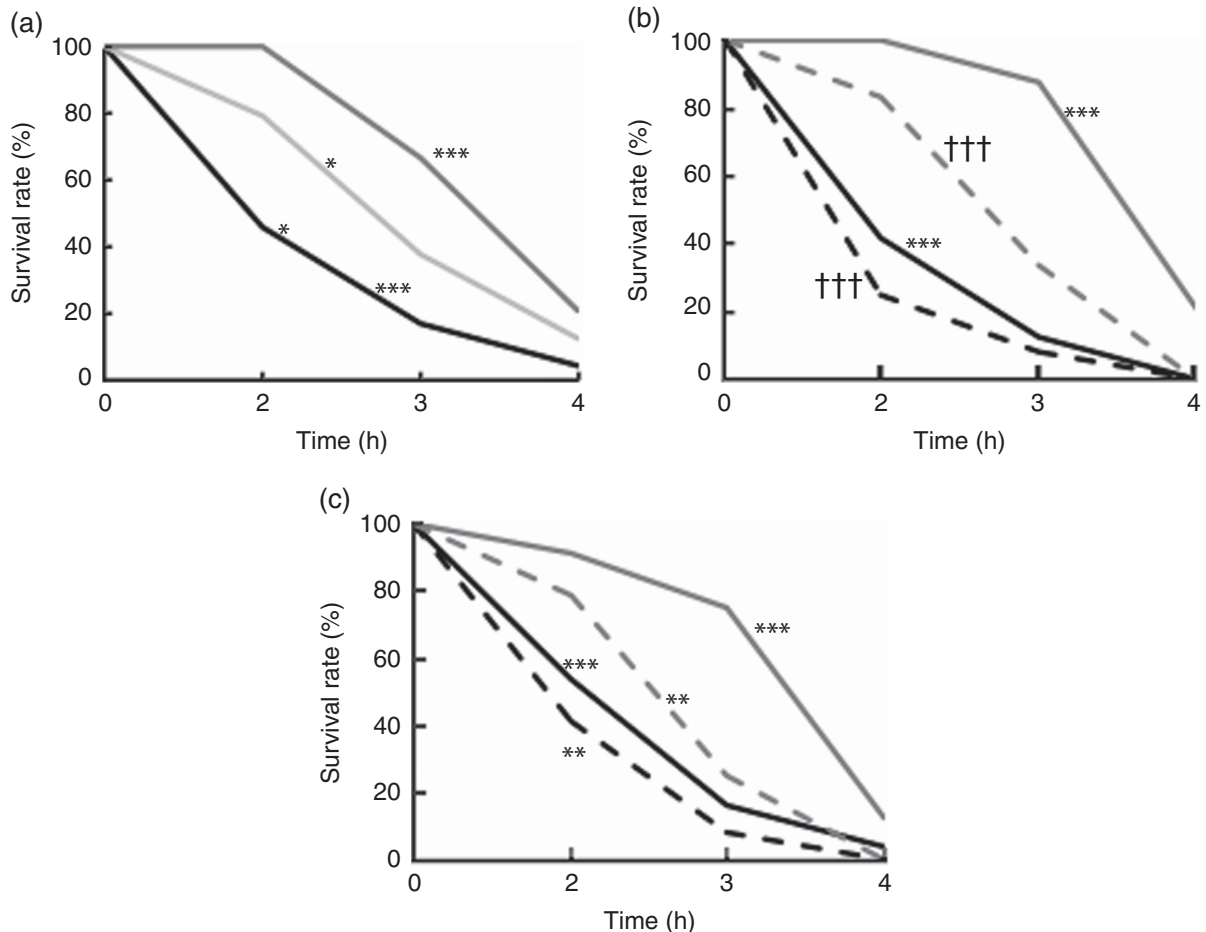

Fig. 4. Oxidative stress tolerance of worms fed Bifidobacterium longum (BL). Synchronised wild-type N2 (a-c), as well as $m g D f 50$ (b) and tm4211, worms (c) were cultured on plates with Escherichia coli (OP50) alone (OP plates; CT) or with killed BL (BL plates; a: $0.5 \mathrm{or} 5.0 \mathrm{mg} / \mathrm{ml}$; b-c: $5.0 \mathrm{mg} / \mathrm{ml}$ ) for $96 \mathrm{~h}$ and then transferred to a $24-\mathrm{well}$ plate with $500 \mu \mathrm{l}$ of $0.3 \% \mathrm{H}_{2} \mathrm{O}_{2}$ (the time of worm transfer was designated as $0 \mathrm{~h}$ ). The survival rate was assessed hourly starting at $2 \mathrm{~h}$ after the transfer. The survival rate at O h was set as 100\%. a: —, CT; —, BL 0.5; —, BL 5.0 (mg/ml); b: —, CT (N2); —, BL 5.0 (N2) (mg/ml); - - - CT (mgDf50); - - -, BL 5.0 (mgDf50) (mg/ml); c: — CT (N2); — BL 5.0 (N2); - - - CT (tm4241); - - - BL 5.0 (tm4241) (mg/ml). * $P<0.05,{ }^{\star \star} P<0.01,{ }^{\star \star *} P<0.005$, ††† $P<0.005$ by log-rank test, $n$ 24 per group. 
captured using a BZ8000 microscope and analysed using the Image software. The fluorescence of control worms was set as $100 \%$, and $>35$ worms were evaluated for each group.

\section{Mitochondria activation assay}

Synchronised worms were cultured on OP or BL plates $(5.0 \mathrm{mg} / \mathrm{ml})$ for $72 \mathrm{~h}$. To evaluate the mitochondrial membrane potential and mitochondrial ROS, $0.5 \mathrm{mg} / \mathrm{ml}$ MitoTracker Orange CMTMRos (Thermo Fisher Scientific, Inc.) and $0.5 \mathrm{mg} / \mathrm{ml}$ MitoTracker Orange $\mathrm{CM}-\mathrm{H}_{2}$ TMRos (Thermo Fisher Scientific) were added into the plates at a volume of $400 \mu \mathrm{l}$. After $24 \mathrm{~h}$, the worms were washed and then fixed with $10 \%$ ethanol. The fluorescence was captured using a BZ8000 microscope and analysed using the ImageJ software. The fluorescence level of control worms was set as $100 \%$, and $>55$ worms/group were analysed.

\section{Cellular localisation of DAF-16}

The cellular localisation of DAF-16 was assessed in TJ356 worms. Synchronised worms were cultured on OP or BL plates $(1 \cdot 0,2 \cdot 0,3 \cdot 0$ or $5.0 \mathrm{mg} / \mathrm{ml})$ for $96 \mathrm{~h}$ and then fixed with $10 \%$ ethanol. Fluorescence images were captured using a BZ8000 microscope and analysed using the ImageJ software. Activated DAF-16 could be observed as bright dots. DAF-16 cellular localisation pattern in the worms can be classified into the following types: nucleus, partially nucleus, and cytoplasmic. More than twenty worms were assessed per group.

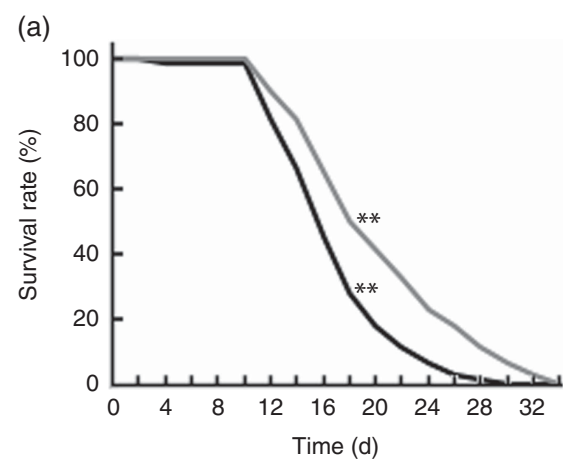

(c)

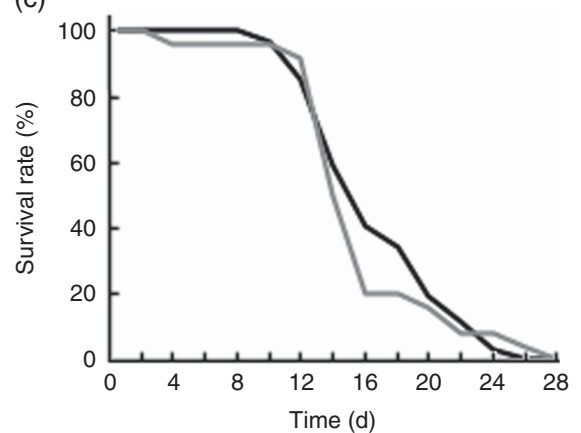

\section{Gene expression analysis}

Synchronised worms were cultured on OP or BL plates $(0.5$ or $5.0 \mathrm{mg} / \mathrm{ml}$ ) for $96 \mathrm{~h}$. For mRNA extraction, the worms were crushed using the Power Masher II and Bio Masher II (Nippi, Inc.). The PrimeScript RT Reagent Kit with gDNA Eraser (Takara Bio Inc.) was used for the complementary DNA synthesis. Subsequently, quantitative PCR (qPCR) was performed using the Thunderbird SYBR qPCR Mix (Toyobo) and gene-specific primers (Table 1) in a Thermal Cycler Dice Real Time System Lite (Takara Bio Inc.) instrument. Actin was used as the reference gene, and each qPCR reaction was performed in triplicate wells.

\section{Statistical analysis}

Data are shown as the means with their standard errors. Tukey's test and log-rank test were used for the data analysis. Graphs were generated using the Microsoft Excel and PowerPoint software (Microsoft Corp.). $P$ values $<0.05$ indicate statistically significant differences.

\section{Results}

\section{Nematode growth and development}

BL supplementation shortened the body length of the worms in a dose-dependent manner (Fig. 1(a)). As assessed by fluorescence, BL supplementation decreased the expression of COL-19 in TP12 worms in a dose-dependent manner (Fig. 1(b)).

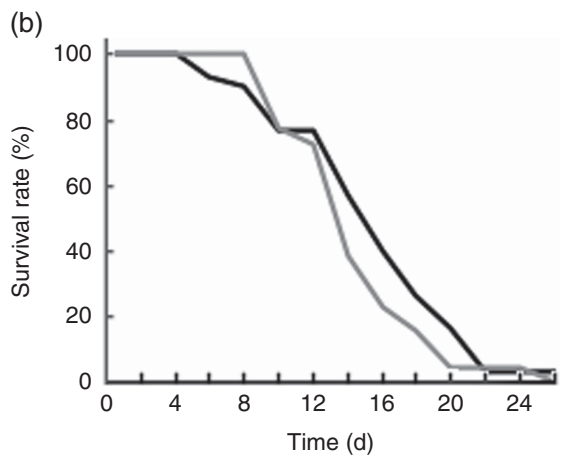

(d)

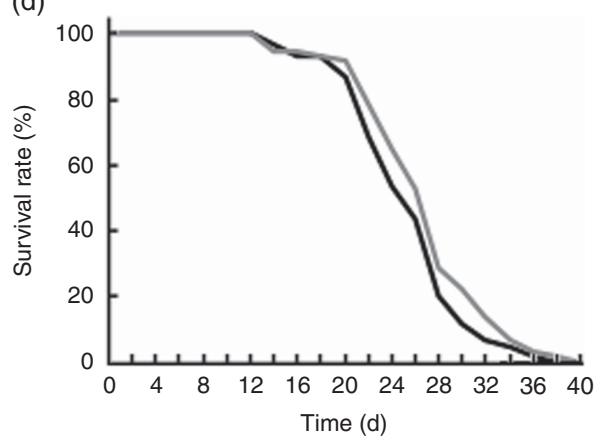

Fig. 5. Life span of worms fed Bifidobacterium longum (BL). Synchronised wild-type N2 (a), MgDf50 (b), ok434 (c) and tm4241 worms (d) were cultured on plates with Escherichia coli (OP50) (OP plates) for $96 \mathrm{~h}$ and then transferred to a new OP plate (CT) or plates with killed $\mathrm{BL}(5.0 \mathrm{mg} / \mathrm{ml}$ ), which was designated as day 0 . The worms were transferred to new plates every $2 \mathrm{~d}$, and the worm survival was assessed on each transfer day. To prevent offspring generation, $0.5 \mathrm{mg} / \mathrm{ml} \mathrm{FUdR}$ was added into the plates at days $-1,0,2$ and 4. a: — , CT; —, BL 5.0 (mg/ml); b: — — CT (mgDf50); — $\longrightarrow$, BL 5.0 (ok434) (mg/ml); d: $\longrightarrow$, CT (tm4241); — BL 5.0 (tm4241) (mg/ml). ${ }^{\star \star} P<0.01$ by log-rank test, $n 60$ per group. 


\section{Anti-ageing effects of Bifidobacterium longum}

Generally, all worms displayed reduced motility over the course of the experiment. However, wild-type N2 worms fed killed BL displayed increased motility compared with control worms fed E. coli alone. At day 9, worms fed $0.5 \mathrm{mg} / \mathrm{ml}$ and $5 \mathrm{mg} / \mathrm{ml} \mathrm{BL}$ showed a 6- and 9-fold higher average of thrashing movements, respectively, compared with those fed E. coli only (Fig. 2(a)). However, BL supplementation failed to conserve the movement of ageing $t m 4241$ worms, whereas $m g D f 50$ worms fed BL displayed reduced motility than those fed E. coli alone (Fig. 2(b)).

Bifidobacterium longum increased the nematode tolerance to heat and oxidative stress

Supplementation with killed BL in wild-type N2 worms improved the worm survival during heat stress in a dosedependent manner (Fig. 3(a)). BL also increased the rate of recovery from heat stress (Fig. 3(b) and (d)) in wild-type N2 worms. Together, these findings suggested that BL increased tolerance to heat stress in $C$. elegans. However, BL did not increase the recovery rate of $m g D f 50$ worms (Fig. 3(c)), but increased that of $t m 4241$ worms (Fig. 3(d)).

Similarly, BL increased the survival rate during oxidative stress in a dose-dependent manner (Fig. 4(a)) in wild-type N2 worms. In contrast to the findings on heat stress, BL also increased the survival rate of both $m g D f 50$ (Fig. 4(b)) and tm4241 worms (Fig. 4(c)).

\section{Bifidobacterium longum affected longevity, fat accumulation and mitochondrial activity}

Wild-type N2 worms fed killed BL showed significantly longer life span when compared with those fed E. coli only (Fig. 5(a)). However, BL did not improve the longevity of $m g D f 50$ (Fig. 5(b)), ok434 (Fig. 5(c)) or tm 4241 worms (Fig. 5(d)).

BL also decreased the fat accumulation in N2 worms in a dose-dependent manner (Fig. 6(a)), and increased mitochondrial membrane potential (Fig. 6(b)) and mitochondrial ROS level (Fig. 6(c)) in N2 worms when compared with those observed in the control worms.

\section{Bifidobacterium longum affected cellular localisation of DAF-16 and expression of its target genes}

As shown by green fluorescence in TJ356 worms, BL induced nuclear localisation of DAF-16 (Fig. 7(b) and (d)) when compared with that observed in TJ356 control worms fed E. coli only (Fig. 7(a) and (c)). Further analyses showed that DAF-16 nuclear localisation was dependent on the dosage of $\mathrm{BL}$ (Fig. 7(e)).

Furthermore, qRT-PCR results showed that BL increased the level of daf-16 mRNA and markedly increased the expression of one of its target genes - $b s p-12.6$ (Fig. 8). Although to a lesser extent, BL also significantly increased the relative mRNA level of hsp-16.2, bsp-70, skn-1, ctl-1, ctl-2 and sod-1.
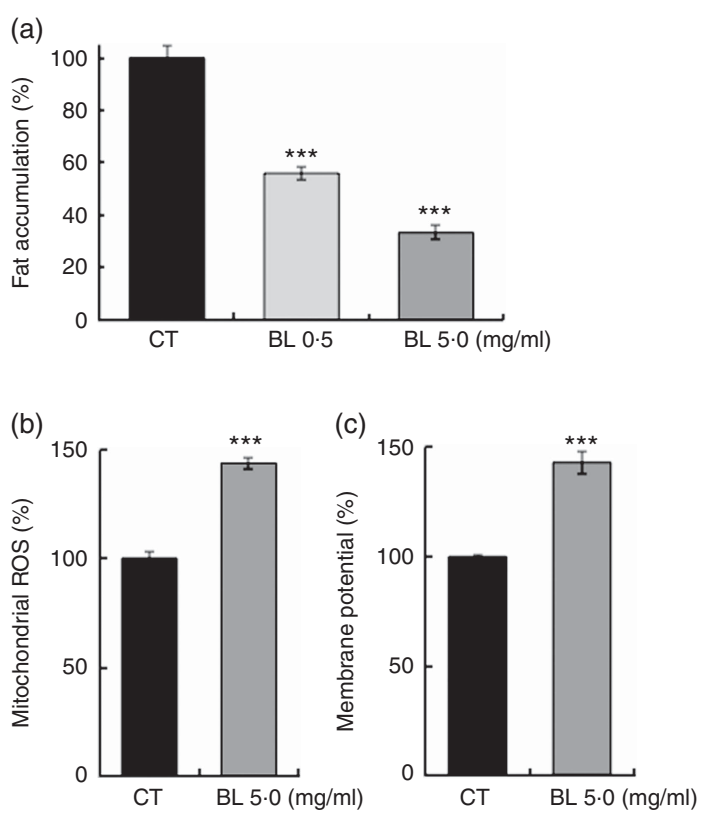

Fig. 6. Fat accumulation and mitochondria activation in worms fed Bifidobacterium longum (BL). (a) Synchronised wild-type N2 worms were cultured on plates with Escherichia coli (OP50) alone (OP plates; CT) or with killed BL (BL plates; 0.5 or $5.0 \mathrm{mg} / \mathrm{ml}$ ) for $96 \mathrm{~h}$. The worms were then fixed with $4 \%$ PFA and stained with Nile red. (b, c) Synchronised worms were cultured on OP (CT) or BL plates $(5.0 \mathrm{mg} / \mathrm{ml})$ for $72 \mathrm{~h}$, and $0.5 \mathrm{mg} / \mathrm{ml}$ MitoTracker Orange CMTMRos and $0.5 \mathrm{mg} / \mathrm{ml}$ MitoTracker Orange $\mathrm{CM}-\mathrm{H}_{2}$ TMRos were added into the plates at a volume of $400 \mu \mathrm{l}$. After $24 \mathrm{~h}$, the worms were washed and fixed with $10 \%$ ethanol. In both assays, the fluorescence was measured and analysed using a BZ8000 microscope and the ImageJ software, respectively. The fluorescence of the control worms was set as $100 \%$. Values are means ( $n>35$ and $n>55$ worms for the two assays, respectively), with their standard errors represented by vertical bars. ROS, reactive oxygen species. ${ }^{\star \star *} P<0.005$ by Tukey's $t$ test.

\section{Discussion}

The present study elucidated several physiological effects of killed BL in C. elegans, including enhanced stress tolerance, increased motility and prolonged life span. Feeding worms with BL affected the growth and development of the worms. As shown by the fluorescence of col-19::GFP (TP12) worms, those fed a high concentration of BL expressed a lower level of COL-19 protein, indicating higher larva ratio and delayed growth on these worms ${ }^{(31,32)}$ without affecting reproduction (online Supplementary Fig. S1). This may be associated with shorter body length observed in worms fed BL (Fig. 1(b)). It is widely thought that stress tolerance, longevity and development are highly related. A previous report showed that stress tolerance and longer life span are typically observed in the event of delayed growth ${ }^{(33)}$.

In this study, BL appeared to enhance tolerance to heat stress (Fig. 3(a)) and $\mathrm{H}_{2} \mathrm{O}_{2}$-induced stress in C. elegans (Fig. 4(a) and (c)) and conserved the motility in aged worms (Fig. 3). Although the motility conservation was not consistently observed throughout the experimental period, BL appeared to improve the worm motility in a dose-dependent manner. Furthermore, BL significantly prolonged the life span of the worms (Fig. 5(a)).

Nevertheless, BL failed to increase the heat stress tolerance in $m g D f 50$ worms (Fig. 3(c)) and did not prolong the life span of 

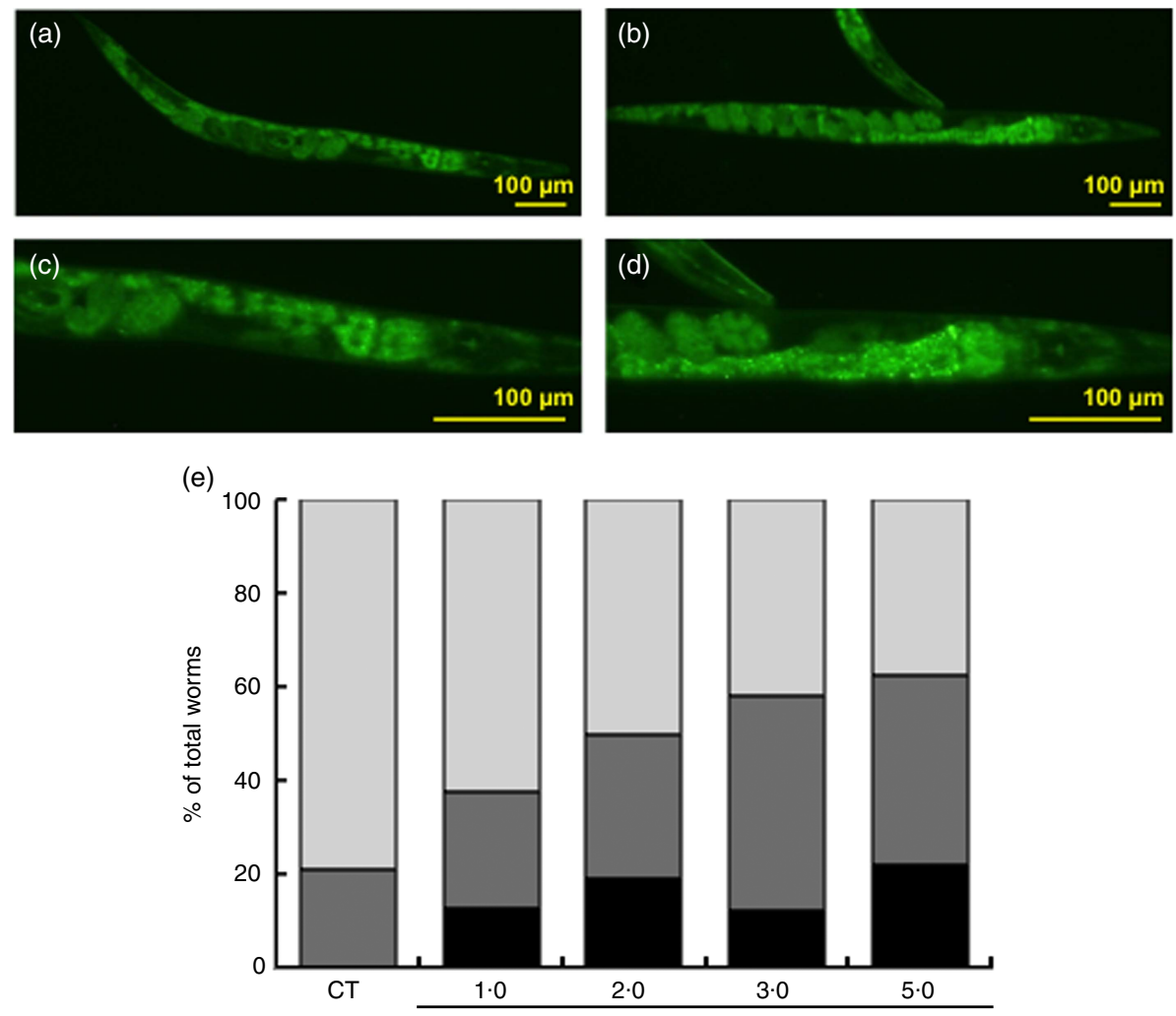

$\mathrm{BL}(\mathrm{mg} / \mathrm{ml})$

Fig. 7. Cellular localisation of DAF-16. The cellular localisation of DAF-16 was evaluated using TJ356 worms. Synchronised worms were cultured on plates with Escherichia coli (OP50) alone (OP plates; CT) or with killed Bifidobacterium longum (BL plates; $1.0,2.0,3.0$ or $5.0 \mathrm{mg} / \mathrm{ml}$ ) for $96 \mathrm{~h}$ and then fixed with $10 \%$ ethanol. Images were captured using a BZ8000 fluorescent microscope and analysed with the ImageJ software. Representative images of (a) control worms (CT) and (b) those given $5.0 \mathrm{mg} / \mathrm{ml} \mathrm{BL}$ are shown. (c, d) Higher-magnification images of panels a and b, respectively. The scale bars indicate $100 \mu \mathrm{m}$. (e) DAF-16 cellular localisation was classified into three types - nuclear, partial nuclear and cytoplasmic - and the results are graphed and presented. e: $\square$, Nuclear; $\square$, partial nuclear; $\square$, cytoplasmic.

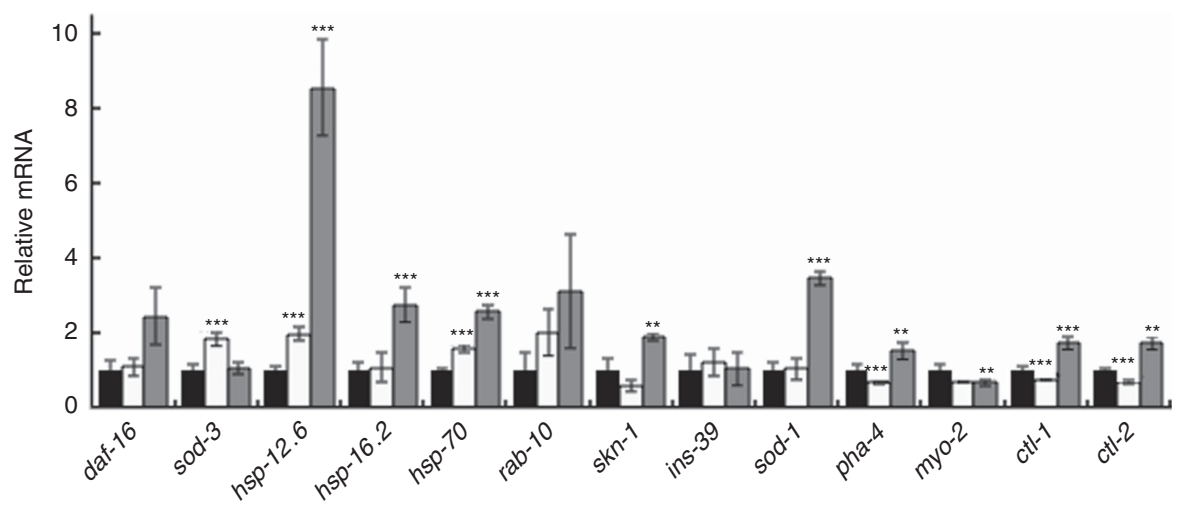

Fig. 8. Gene expression analysis of worms fed Bifidobacterium longum (BL). Synchronised worms were cultured on plates with Escherichia coli (OP50) alone (OP plates; CT) or with killed BL (BL plates; 0.5 or $5.0 \mathrm{mg} / \mathrm{ml}$ ) for $96 \mathrm{~h}$. qRT-PCR analysis was performed using the Thermal Cycler Dice Real Time System Lite and Thunderbird SYBR qPCR Mix, and actin was used as the reference gene in triplicate wells. Values are means with their standard errors represented by vertical bars. $\square, \mathrm{CT} ; \square, \mathrm{BL} 0.5 ; \square, \mathrm{BL} 5.0$ (mg/ml). ${ }^{\star *} P<0.01,{ }^{\star \star *} P<0.005$ by Tukey's $t$ test.

$m g D f 50$ and ok434 worms (Fig. 5(b) and (c)). These results suggested that heat stress tolerance and longevity was mediated by DAF-16 and SIR-2.1, respectively. This notion was supported by the finding that $\mathrm{BL}$ increased $b s p-12.6$ expression (Fig. 7). Furthermore, BL induced the nuclear localisation of DAF-16 (Fig. 6(e)). These findings suggested that BL dose-dependently activated DAF-16. Previously, it was shown that DAF-16 nuclear translocation promotes longevity in C. elegans ${ }^{(18)}$. In addition, a previous study demonstrated that SIR-2.1 deacetylates and activates DAF-16 ${ }^{(34)}$. Therefore, results of these and the present studies suggested that BL activates DAF-16 via SIR-2.1 to induce longevity.

In this study, the mRNA level of sod-3, a target gene of $d a f-16$, did not increase, but it seems to be owing to the following reasons. The nuclear translocation of SMK-1, together with DAF-16, induces transcription of $s o d-3^{(35)}$, whereas co-localisation of 
DAF-16 with HSF-1 induces the gene expression of $b s p$ $12.6^{(35,36)}$. In this study, HSF-1 could be activated and translocated in the nucleus with DAF-16. This notion was supported by the result that $\mathrm{BL}$ up-regulated the expression of $h s p-16.2$ and $h s p-70$, the target genes of HSF-1. Therefore, the physiological effect of BL was due to DAF-16, but the contribution of these effects is thought to be $h s p-12.6$ instead of sod-3.

This study also demonstrated that BL decreased fat accumulation (Fig. 6(a)) and increased mitochondrial membrane potential and ROS level (Fig. 6(b) and (c)) in worms. It is hypothesised that $\mathrm{BL}$ activated the mitochondria and oxidised fat in the process in C. elegans $^{(37)}$. Typically, longer-living worms have lower mitochondrial ROS levels; however, a mild increase in ROS level was reported to induce mitohormesis and prolong life $\operatorname{span}^{(37,38)}$.

Here, BL increased the recovery rate from heat stress (Fig. 3(d)) and $\mathrm{H}_{2} \mathrm{O}_{2}$ stress tolerance (Fig. 4(c)) in $t m 4241$ and wild-type N2 worms, suggesting that BL-induced heat and $\mathrm{H}_{2} \mathrm{O}_{2}$ stress tolerance was independent of SKN-1. However, BL failed to conserve the movement (Fig. 2(b)) and prolong life span (Fig. 5(d)) of tm4241 worms. These results suggested that the longevity effect of BL was only partially mediated by SKN-1. Other studies have reported that other probiotics, Bifidobacterium infantis and Lactobacillus gasseri SBT2055, prolong the life span of worms via SKN-1, but is independent of DAF-16 ${ }^{(39,40)}$. Surprisingly, results of this study showed that the anti-ageing effect of killed BL (BR-108) was partially mediated by SKN-1 and mainly via DAF-16. Although BL supplementation induced resistance to $\mathrm{H}_{2} \mathrm{O}_{2}$ stress in this study (Fig. 4(a) and (c)), the mechanism was unclear. Gene expression analysis showed increased $\mathrm{ctl}-1$ and ctl-2 expression in BL-fed worms (Fig. 8). Catalases in worms may be activated to degrade $\mathrm{H}_{2} \mathrm{O}_{2}$; however, further studies are needed to elucidate the signalling pathway involved.

This study may be used as a model study to determine the effect of probiotics on ageing. Further studies evaluating the physiological effects of probiotics in higher animals are needed to better understand the benefit of killed probiotics.

\section{Acknowledgements}

This work was supported in part by Grants-in-Aid for Scientific Research and Education from the University of Tsukuba. The Bifidobacterium longum (BR-108) was supplied by Combi Corporation.

T. S. and K. S. conceived and designed the study, analysed data, wrote the paper and made manuscript revisions. T. S. performed all experiments. K. S. supervised the study as the principal investigator. All authors read and approved the final manuscript.

The authors declare that there are no conflicts of interest.

\section{Supplementary material}

For supplementary material/s referred to in this article, please visit https://doi.org/10.1017/S0007114518001563

\section{References}

1. Stiernagle T (2006) Maintenance of C. elegans. In WormBook, pp. 1-11. Caenorhabditis Genetics Center, University of Minnesota, Minneapolis, MN. http://dx.doi.org/10.1895/wormbook. 1.101.1 (accessed December 2017).
2. Shintani H, Furuhashi T, Hano H, et al. (2012) Physiological effects of salmon milt nucleoprotein on movement, stress tolerance and lifespan of C. elegans. Food Nutr Sci 3, 48-54.

3. Seo HW, Cheon SM, Lee MH, et al. (2015) Catalpol modulates lifespan via DAF-16/FOXO and SKN-1/Nrf2 activation in Caenorhabditis elegans. Evid Based Complement Alternat Med 2015, 524878 .

4. Zhang J, Lu L \& Zhou L (2015) Oleanolic acid activates daf-16 to increase lifespan in Caenorhabditis elegans. Biochem Biophys Res Commun 468, 843-849.

5. Ha CW \& Huh WK (2011) The implication of Sir2 in replicative aging and senescence in Saccharomyces cerevisiae. Aging (Albany NY) 3, 319-324.

6. Medvedik O, Lamming DW, Kim KD, et al. (2007) MSN2 and MSN4 link calorie restriction and TOR to sirtuin-mediated lifespan extension in Saccharomyces cerevisiae. PLoS Biol 5 , e261.

7. Lithgow GJ, White TM, Melov S, et al. (1995) Thermotolerance and extended life-span conferred by single-gene mutations and induced by thermal stress. Proc Natl Acad Sci U S A 92 , 7540-7544.

8. Rizki G, Iwata TN, Li J, et al. (2011) The evolutionarily conserved longevity determinants HCF-1 and SIR-2.1/SIRT1 collaborate to regulate DAF-16/FOXO. PLOS Genet 7, e1002235.

9. Hwangbo DS, Palmer M, Tatar M, et al. (2004) Drosophila $\mathrm{dFOXO}$ controls lifespan and regulates insulin signalling in brain and fat body. Nature 429, 562-566.

10. Ogg S, Paradis S, Gottlieb S, et al. (1997) The Fork head transcription factor DAF-16 transduces insulin-like metabolic and longevity signals in C. elegans. Nature 389, 994-999.

11. Tissenbaum HA \& Guarente L (2001) Increased dosage of a sir-2 gene extends lifespan in Caenorhabditis elegans. Nature 410, 227-230.

12. Lee SS, Kennedy S, Tolonen AC, et al. (2003) DAF-16 target genes that control C. elegans life-span and metabolism. Science 300, 644-647.

13. Klotz LO, Sánchez-Ramos C, Prieto-Arroyo I, et al. (2015) Redox regulation of FoxO transcription factors. Redox Biol $\mathbf{6}$, 51-72.

14. Lee RY, Hench J \& Ruvkun G (2001) Regulation of C. elegans DAF-16 and its human ortholog FKHRL1 by the daf-2 insulinlike signaling pathway. Curr Biol 11, 1950-1957.

15. Honda Y \& Honda S (1999) The daf-2 gene network for longevity regulates oxidative stress resistance and Mnsuperoxide dismutase gene expression in Caenorhabditis elegans. FASEB J 11, 1385-1393.

16. Zhao Y, Yang R, Rui Q, et al. (2016) Intestinal insulin signaling encodes two different molecular mechanisms for the shortened longevity induced by graphene oxide in Caenorbabditis elegans. Sci Rep 6, 24024.

17. Hsu AL, Murphy CT \& Kenyon C (2003) Regulation of aging and age-related disease by DAF-16 and heat-shock factor. Science 300, 1142-1145.

18. Tissenbaum HA \& Guarente L (2001) Increased dosage of a sir-2 gene extends lifespan in Caenorhabditis elegans. Nature 410, 227-230.

19. Rogina B \& Helfand SL (2004) Sir2 mediates longevity in the fly through a pathway related to calorie restriction. Proc Natl Acad Sci U S A 101, 15998-16003.

20. Johnson TE, Henderson S, Murakami S, et al. (2002) Longevity genes in the nematode Caenorhabditis elegans also mediate increased resistance to stress and prevent disease. I Inherit Metab Dis 25, 197-206.

21. Lam EW, Brosens JJ, Gomes AR, et al. (2013) Forkhead box proteins: tuning forks for transcriptional harmony. Nat Rev Cancer 7, 482-495. 
22. Katoh M \& Katoh M (2004) Human FOX gene family (Review) Int J Oncol 5, 1495-1500.

23. Kim J, Ishihara N \& Lee TR (2014)) A DAF-16/FoxO3adependent longevity signal is initiated by antioxidants. Biofactors 40, 247-257.

24. Jünger MA, Rintelen F, Stocker H, et al. (2003) The Drosophila forkhead transcription factor FOXO mediates the reduction in cell number associated with reduced insulin signalling. $J$ Biol 2, 20.

25. Metchnikoff E \& Chalmers-Mitchell P (1908) The Prolongation of Life. Optimistic Studies. New York: GP Putnam's Sons.

26. Anukam KC \& Reid G (2007) Probiotics: 100 years (19072007) after Elie Metchnikoff's observation. In Communicating Current Research and Educational Topics and Trends in Applied Microbiology, pp. 466-474 [A Méndez-Vilas, editor]. Badajoz: Formatex Research Center.

27. Mitsuoka T \& Hayakawa K (1972) Die Faekalflora bei Menschen. I. Mitteilung: die Zusammensetzung der Faekalflora der verschiedenen Altersgruppen (The fecal flora of man 1. Communication: The composition of the fecal flora of ten healthy human volunteers with special reference to the Bacteroides fragilis group and Clostridium difficile). Zentralbl Bakteriolk Hyg I Abt Orig A223, 333-342.

28. Zhang LL, Chen X, Zheng PY, et al. (2010) Oral Bifidobacterium modulates intestinal immune inflammation in mice with food allergy. J Gastroenterol Hepatol 5, 928-934.

29. Noriyuki I (2014) Immunomodulatory effects of bifidobacteria and their mechanisms. J Intest Microbiol 28, 141-146.

30. Singh J, Rivenson A, Tomita M, et al. (1997) Bifidobacterium longum, a lactic acid-producing intestinal bacterium inhibits colon cancer and modulates the intermediate biomarkers of colon carcinogenesis. Carcinogenesis 4, 833-841.
31. Prasanth MI, Santoshram GS, Bhaskar JP, et al. (2016) UltravioletA triggers photoaging in model nematode Caenorhabditis elegans in a DAF-16 dependent pathway. Age (Dordr) 38, 27.

32. Thein MC, McCormack G, Winter AD, et al. (2003) Caenorbabditis elegans exoskeleton collagen COL-19: an adultspecific marker for collagen modification and assembly, and the analysis of organismal morphology. Dev Dyn 226, 523-539.

33. Saul N, Pietsch K, Menzel R, et al. (2009) Catechin induced longevity in $C$. elegans: from key regulator genes to disposable soma. Mech Ageing Dev 130, 477-486.

34. Berdichevsky A, Viswanathan M, Horvitz HR, et al. (2006) C. elegans SIR-2.1 interacts with 14-3-3 proteins to activate DAF-16 and extend life span. Cell 125, 1165-1177.

35. Wolff S, Ma H, Burch D, et al. (2006) SMK-1, an essential regulator of DAF-16-mediated longevity. Cell 124, 1039-1053.

36. Hsu AL, Murphy CT \& Kenyon C (2003) Regulation of aging and age-related disease by DAF-16 and heat-shock factor. Science 300, 1142-1145.

37. Zarse K, Bossecker A, Muller-Kuhrt L, et al. (2011) The phytochemical glaucarubinone promotes mitochondrial metabolism, reduces body fat, and extends lifespan of Caenorhabditis elegans. Horm Metab Res 43, 241-243.

38. Zarse K, Schmeisser S, Groth M, et al. (2012) Impaired insulin/ IGF1 signaling extends life span by promoting mitochondrial L-proline catabolism to induce a transient ROS signal. Cell Metab 15, 451-465.

39. Komura T, Ikeda T, Yasui C, et al. (2013) Mechanism underlying prolongevity induced by bifidobacteria in Caenorbabditis elegans. Biogerontology 14, 73-87.

40. Nakagawa H, Shiozaki T, Kobatake E, et al. (2016) Effects and mechanisms of prolongevity induced by Lactobacillus gasseri SBT2055 in Caenorhabditis elegans. Aging Cell 15, 227-236. 